\title{
Proposal for a Division of Responsi- bility among American Libraries in the Acquisition and Recording of Library Materials
}

Should the acquisition program of research libraries of the country be inclusive or selective? The following proposal looks toward inclusiveness through cooperation.

$\mathrm{M}^{\mathrm{ONEY}}$ can be saved by reducing du$\mathrm{M}$ plication of work and materials. Library resources can be made more widely and more readily available by centralizing information and they can be increased by coordinating the efforts of research libraries. One or another of these general propositions, or a combination of them, has been involved in every cooperative plan that librarians have undertaken or discussed.

If the discussions have been more numerous than the achievements, the latter are far from insignificant. Many possibilities have long been evident, and the American Library Association, in its charter, gave as one of its purposes the inducing of "cooperation in all departments of bibliothecal science and economy." A plan for expansion of Poole's Index by cooperative indexing of periodicals was unanimously adopted at the first meeting of the Association in 1876; this first great periodical index is then, in part, a product of library cooperation.
Still earlier, nearly a century ago, Charles Coffin Jewett, then librarian of the Smithsonian Institution in Washington, proposed a plan for centralized cataloging that, if it had been carried out successfully, might have saved the libraries of the country millions of dollars. The scheme failed, partly because of mechanical difficulties with the stereotype plates that he hoped to use for master copy and partly because he was ahead of his time. But, after Herbert Putnam became Librarian of Congress, the distribution of printed cards was begun and centralized cataloging became a reality on a large scale. There have been various other efforts toward cooperative cataloging, and the project begun ten years ago to supply cards for books not acquired by the $\mathrm{Li}$ brary of Congress will, it is hoped, expand considerably in the immediate future under Mr. MacLeish's administration.

Perhaps the most recent realization of a means of securing economies by cooperation is the New England Deposit Library, the first building to be erected for cooperative storage of little-used library materials.

In the field of making resources available, interlibrary loans have been advo- 
cated from the beginning and have grown steadily. But interlibrary loan-or its most recent adjunct, microphotographic reproduction-is possible only after the materials to be borrowed or filmed have been located; union lists and union catalogs are prerequisites.

Early accomplishments in this direction included lists of specialized material, such as the Census of Incunabula and Sabin's Dictionary of Books Relating to America. The most important achievements in this group are, of course, the works edited by Winifred Gregory (Mrs. James T. Gerould) - two editions of the Union List of Serials and the union lists of newspapers, of foreign documents, and of international congresses.

Development of union catalogs and bibliographical centers has seemed to be the best way to make it possible to locate individual books. Regional catalogs have been established in recent years, but the Union Catalog at the Library of Congress is the major development. With an estimated I I,500,000 locations for $7,500,000$ different titles and editions-about 60 per cent of the titles in American research libraries-it is extremely useful. Plans for expansion as proposed by Robert B. Downs should be encouraged.

A good deal, then, has been done to make resources accessible, but very little, comparatively, has been accomplished toward increasing resources by cooperative acquisition. Surveys of localities and regions have been made and there have been agreements covering specific fields in certain areas such as New York City, Chicago, and between the universities of North Carolina and Duke. The relative lack of progress in cooperation of this sort undoubtedly results from the difficulties involved-the responsibilities of individ- ual libraries, legal restrictions on their freedom of action, and obstacles to changing established practices. The problem is complex and, as in most other cooperative efforts, an initial investment is required.

\section{Cooperation Is Desirable}

There is, however, general agreement that cooperation through library specialization in the different fields of research is desirable and this agreement has been expressed at many meetings of the American Library Association and the Association of Research Libraries; in reports received by the director of the Experimental Division of Library Cooperation at the Library of Congress as a result of his meetings with librarians in the year 194I-42; and in the hearty approval given by presidents, deans, and library committees of educational institutions throughout the country to the proposal that is to be described in this article.

Indeed, the advantages of cooperation are so obvious that everyone believes in it theoretically, at least, just as everyone believes in world peace. The difficulty is to determine a practicable first step. And, in suggesting such a step, it must be emphasized that regimentation is not wanted. The library resources of the country ought to be made as nearly complete as possible, resources should become more readily available, and it should not be necessary to invest in the research needed to catalog a book every time another copy of that book is acquired by another library.

A possible solution is offered by a "Proposal for a Division of Responsibility among American Libraries in the Acquisition and Recording of Library Materials," which was drawn up by a committee* of calf. 
the Librarian's Council, a group of librarians invited to advise the Librarian of Congress concerning the relation of the Library of Congress to other libraries. This was placed in the hands of librarians of many of the larger libraries of the country some months ago and was approved by authorized representatives of the American Library Association, the Association of Research Libraries, and the Council of National Library Associations, as well as by the American Council of Learned Societies. The essential features of this proposal are as follows:

\section{A}

It is proposed that libraries having research collections join in a cooperative undertaking limited for the time being to current materials in the Latin alphabet. (It is hoped that Slavic materials in the Cyrillic alphabet can be added in the not too distant future.) The term "materials" refers for the time being only to books and pamphlets in the regular book trade, but plans will be prepared later to include public documents, serials, periodicals, and at least a selection of newspapers.

As to these current materials in the Latin alphabet, the cooperating institutions would agree upon a common policy with the following aims:

I. That at least one copy of every book and pamphlet, published anywhere in the world following the effective date of the agreement which might reasonably be expected to have interest to a research worker in America, shall be acquired and made available promptly after publication by some one of the cooperating libraries. 2. That each item so acquired shall be promptly cataloged (if possible by centralized or cooperative cataloging), , listed promptly in the Union Catalog at the Library of Congress and also in a new classed union catalog to be established at the Library of Congress, from which subject catalogs of limited fields may later be published in book form or otherwise, as demand suggests.

\section{B}

To carry out these policies, it is proposed that a competent staff be employed to make possible the following preliminary steps at the earliest possible moment after money has become available for the purpose. It is hoped that steps (I) through (6) below will be completed promptly enough so that the plan can be put into operation immediately after the close of the war.

I. The staff will prepare for submission to cooperating libraries a plan subdividing human knowledge into carefully defined units, each as distinct as possible. It is suggested that the Library of Congress system of classification might serve as a basis for most of this work.

2. The staff will make a survey of existing special collections as a basis for the allocation of responsibility.

3. The staff will make a survey of world book production by country and by subject and estimate the adequacy of present purchases and the probable additional expense involved in making current acquisitions complete instead of selective.

4. Each cooperating library will then be asked to name the fields of its particular interest in which it would be willing to specialize and to assume responsibility for a comprehensive (not a selective) coverage within the terms of Section A.

5. On the basis of these offers of specialization, the headquarters staff will try to arrange for the allocation of fields for which no offer has been made and will suggest, in cases where several offers have been made for the same field, the allocation which seems to it most practicable. 6. After the presidents, deans, trustees, committees, and librarians of each cooperating institution have reached agreement, each library will announce the fields for which it is ready to accept formal responsibility.

7. Nothing in the proposed arrangement will limit in any way the freedom of any cooperating institution to purchase any materials it desires to secure. Librarians accepting this proposal will merely accept affirmative responsibility for the completion of certain fields, retaining the right 
to abandon any field after reasonable notice of an intention to do so. In other fields, including those assigned for complete coverage to others, libraries will of course be free to purchase as their needs indicate.

8. As soon as the allocation of fields is completed, the headquarters staff will publish in appropriate professional journals the list of allocations made and accepted, in order that the responsibilities of each library under the plan may be known to all librarians and all interested users of libraries.

\section{C}

In practical operation, this proposal would require the following action by each subscribing library:

I. The prompt acquisition of all current publications in its allotted fields by ordering all titles of research interest listed in the national trade bibliographies and also those in standard reviews. This may be done by each library ordering directly the books within the field for which it assumes responsibility or with the aid of agents, particularly in the smaller countries, who may collect and ship all books for their country to a central office in the United States for distribution.

2. The prompt transmission to the $\mathrm{Li}$ brary of Congress of

a. A catalog card for each title in a form suitable for use as copy for cooperative cataloging as well as for insertion in the Union Catalog;

b. A card suitable for filing in a new classed catalog to be maintained in the Library of Congress, from which printed subject bibliographies may later be drawn if the demand requires.

It may prove wise to arrange for centralized cataloging of some books, particularly those in minor languages.

\section{D}

It is proposed that the program outlined in section $C$ be put into effect as soon after the close of the war as possible.

\section{E}

In addition to carrying through the steps enumerated in section B above, the headquarters staff of this project would make plans and prepare a budget for future operations, including

I. Acquisition abroad. It is anticipated that it may prove desirable for the central office of the project to conduct correspondence with agencies in many, if not all, foreign countries, and the central office may even have to take charge of the buying from certain countries and of materials in certain languages.

2. Cataloging. In the same way it may prove desirable for the central office to act as the representative of the participating libraries in the cooperative cataloging of books in certain languages. If these books are purchased through a central office, an opportunity for centralized cataloging will be offered or the office might farm out such materials to properly equipped libraries for cooperative cataloging.

3. Classed Union Catalog. Here the central office would have no very serious role to play but might have to supervise the provision of cards to the Library of Congress.

4. Change in assignments as they become desirable or necessary.

The cost of the central office after the first two years cannot be estimated at this time, but it should be organized in such a way that it can become self-supporting in not less than five years.

Two major criticisms of the foregoing proposal have been made. First, it has been asserted that the plan is too large to be carried out and that the attempt is useless. The sponsors do not hesitate to admit the magnitude of the project and the difficulties that are sure to arise but they are convinced that the results will justify a real effort along these lines and that information and experience of great value for future planning will be gained.

Second is the objection that inclusive acquisition of the sort proposed ignores the fact that selection is fundamental in 
the philosophy of librarianship. Here the sponsors reply that they agree as to the importance of selection but that no librarian or group of librarians is wise enough to be sure of just what will and will not be needed at some future date, while a relatively slight addition to-or reallocation of - the funds now expended by American research libraries will insure us against errors of judgment by preserving at least one copy of each book somewhere in the country. When they know that this safeguard is being taken, then librarians, except in the field or fields for which they have taken inclusive responsibility, should be free to buy selectively without misgivings.

\section{Funds Not Yet Available}

As has been noted, the foregoing proposal was approved by the American Council of Learned Societies and by the appropriate library organizations. Efforts to obtain funds for putting it into operation have not, however, been successful.

The sponsors of the proposal are unwilling to give up. They are continuing their attempts to obtain foundation support but immediate success does not appear likely and valuable time is being lost. It is of great importance that the preliminary steps be completed before the war is over.

It is possible that the money might be raised among interested libraries. If each member of the Association of Research Libraries would give four hundred dollars per year, or perhaps somewhat less? for two years, and if a little help could be obtained elsewhere, it should be possible to proceed.

Finally, an alternative would be to concentrate on certain phases of the plan or to deal only with material from Latin America, some of the minor European countries, Russia, or China, as representing areas where present acquisitions are most inadequate. In this way a good deal might be learned at small expense and librarians would later be in a better position to develop the proposal on a broad scale. With this in mind, a special session of the Association of Research Libraries was held recently, and proposals were made for action in the areas mentioned.

It is hoped, however, that it need not be long before the comprehensive program can be attempted. There seems to be little question of the desirability of the ends in view. American research libraries will not be contributing to scholarship as adequately and as economically as they ought until every book needed by research workers is acquired by some American library soon after publication, is listed in central union author and subject catalogs, is made available to other institutions by interlibrary loan or microfilm, and need be cataloged only once.

\section{Book Sources in Spain}

SPANish вoOK DEALERS AND PUBLISHers have been listed as of 1943 by the Instituto Nacional del Libro Espanol. The list is reputedly complete, containing one thousand seven hundred names and consisting of six parts: publishers in Madrid, Barcelona, and the provinces; booksellers in Madrid, Barcelona, and the provinces. A copy has been received by the Library of Congress which has made the list a part of its collections to be available for use, interlibrary loan, or photocopying. 